\title{
Effect of oral vitamin $C$ on serum hepcidin level, iron status and inflammation among hemodialysis patients with functional iron deficiency anaemia
}

\author{
Maha A. Behairy ${ }^{* \oplus}$, Ahmed Gharib $^{1}$, Mahmoud Zaki ${ }^{1}$, Reem El Sharabasy ${ }^{10}$
}

\begin{abstract}
Introduction: Hepcidin is a key regulatory peptide in iron homeostasis, the pathogenesis of functional iron deficiency (FID) anemia and erythropoiesis-stimulating agent (ESA) resistance is contributed to the inflammatory mediated increase in the serum hepcidin levels among prevalent hemodialysis (HD) patients.

Objectives: To test the reducing therapeutic effect of oral vitamin $\mathrm{C}$ supplements on hepcidin levels and iron status among HD patients with FID anemia.

Patients and Methods: This study is an interventional prospective cohort study; 48 prevalent HD patients were enrolled. Group one: 31 patients who received the conventional treatment of erythropoietin stimulating agents together with oral supplementation of vitamin $\mathrm{C} 500$ mg every other day dose for 3 months. Group two: 17 patients who received only the conventional therapy of erythropoietin stimulating agents. Patients with hemoglobin level $<11 \mathrm{~g} / \mathrm{dL}$, ferritin level $>200 \mathrm{ng} / \mathrm{mL}$ and transferrin saturation (TSAT) $>20 \%$ were included. Laboratory parameters: serum hepcidin, high-sensitivity C-reactive protein (hs-CRP) titre, CBC, and iron indices were measured at baseline and after 3 months.

Results: On comparing the two groups, oral vitamin $\mathrm{C}$ in group 1 resulted in a statistically significant reduction in hepcidin levels [mean $2506.456 \pm 1320.53 \mathrm{pg} / \mathrm{mL}$ to $1748.396 \pm 1432.28 \mathrm{pg} / \mathrm{mL}(P=0.03)]$, and a significant reduction in hs-CRP level [mean $8603.236 \pm 2547.77$ $\mathrm{ng} / \mathrm{mL}$ to $5611.296 \pm 2829.27 \mathrm{ng} / \mathrm{mL}](P=0.001)$ after three months of treatment in comparison to control group. A decrease of EPO requirement and elevation of hemoglobin level were observed in a study group with oral vitamin $\mathrm{C}$.

Conclusion: Oral vitamin C may be a promising therapy in decreasing serum hepcidin and inflammatory markers among prevalent HD patients with FID anemia.

Keywords: Vitamin C, Hemodialysis, Hepcidin, Iron deficiency, Anaemia

Citation: Behairy MA, Gharib A, Zaki M, El Sharabasy R. Effect of oral vitamin C on serum hepcidin level, iron status and inflammation among hemodialysis patients with functional iron deficiency anaemia. J Renal Endocrinol. 2021;7:e16. doi: 10.34172/jre.2021.16.

Copyright (c) 2021 The Author(s); Published by Nickan Research Institute. This is an open-access article distributed under the terms of the Creative Commons Attribution License (http://creativecommons.org/licenses/by/4.0), which permits unrestricted use, distribution, and reproduction in any medium, provided the original work is properly cited.
\end{abstract}

\section{Introduction}

Functional iron deficiency (FID) is a major cause of persistent anemia in hemodialysis (HD) patients. It was vaguely detected to be caused by chronic inflammatory status and renal dysfunction until the discovery of hepcidin, which described a large part of the pathophysiologic mechanism (1). Hepcidin, a peptide hormone synthesized by the liver, is the central regulatory module for systemic iron homeostasis by decreasing iron absorption from the duodenum, iron release from the macrophages involved in recycling senescent red blood cells, and iron release from iron-storing hepatocytes. The net consequence of elevated hepcidin is decreased iron transfer into the blood plasma, leading to FID (2).

Hepcidin is partially removed from the body by nephron filtration and degradation in the proximal tubule. With diminishing renal function, the renal excretion and degradation of hepcidin are reduced while its hepatic production is increased by the inflammatory stimuli marked by elevated interleukin 6 (IL-6). As a result, the blood hepcidin level is elevated in dialysis patients causing FID (2). Iron metabolism, including de novo and recycled iron, is under the functional control of a recently discovered peptide, designated hepcidin $(3,4)$. Vitamin C can reduce ferric iron $\left(\mathrm{Fe}^{3+}\right)$ into the readily absorbable ferrous form $\left(\mathrm{Fe}^{2+}\right)$, iron exits enterocytes by ferroportin located in the basolateral membrane of enterocytes (4). Larger erythropoietin (EPO) doses and parenteral vitamin $\mathrm{C}$ were used to improve renal anemia in uremic patients.

While the mechanistic relationship between EPO and hepcidin expression was known recently, the relationship between vitamin $\mathrm{C}$ and serum hepcidin levels among $\mathrm{HD}$ patients is still unclear and there are limited studies about the clinical therapeutic value of oral vitamin $\mathrm{C}$ among $\mathrm{HD}$ patients with FID. 


\section{Implication for health policy/practice/research/ medical education}

The appropriate management of anemia is crucial for improving quality of life as well as mortality in chronic kidney disease patients. This clinical research observed the therapeutic impact of low doses of oral vitamin $\mathrm{C}$ on the inflammation-mediated hepcidinferroportin pathway, the main contributing factor in the pathogenesis of functional iron deficiency anemia among chronic kidney disease patients on regular hemodialysis in clinical practice. The effective dose of vitamin $\mathrm{C}$, which has also a beneficial anti-inflammatory effect, with low hazards, needs further clinical trials.

\section{Objectives}

We aimed to study the short-term effect of oral vitamin C therapy on serum hepcidin level and iron indices among HD patients

\section{Patients and Methods}

\section{Study design}

This study is an interventional prospective cohort study. Forty-eight prevalent HD patients participated in the study who were randomly assigned into two groups; a study group who received oral (ascorbic acid) vitamin C $500 \mathrm{mg}$ every other day after HD sessions together with erythropoiesis-stimulating agents (ESAs) and IV (intravenous) iron therapy, and a control group who received only ESAs together with IV iron therapy. Patients' eligibility criteria; patients were eligible to participate in the study if they were clinically stable chronic HD patients maintained on three sessions per week using bicarbonate dialysate and heparin as an anticoagulant, patients' age $\geq 18$ years with FID anemia defined as hemoglobin level $<11 \mathrm{~g} / \mathrm{dL}$, ferritin level $>200 \mathrm{ng} / \mathrm{mL}$ and transferrin saturation $($ TSAT) $>20 \%$ (5). Patients excluded from the study were patients with non-renal causes of anemia other than iron deficiency, patients with evidence of active or occult bleeding, patients who received a blood transfusion within the last four months, patients with end-stage liver disease, or chronic hypoxia, or those with history of recent hospitalization or infection requiring antibiotics within the last four weeks, patients with chronic inflammatory states and patients with known sensitivity to vitamin C.

CONSORT flow diagram of the study was illustrated in Figure 1. The objectives of this prospective study to evaluate the clinical value of oral vitamin $\mathrm{C}$ doses in reducing high serum hepcidin levels in $\mathrm{HD}$ patients and the impact of vitamin $\mathrm{C}$ as adjuvant therapy on inflammatory markers as high-sensitivity C-reactive protein (hs-CRP) titer reduced erythropoietin resistance, raised hemoglobin level, and impact of oral vitamin C low doses on iron profile parameters.

Patients were subjected to detailed history taking and thorough clinical examination. Laboratory investigations included $\mathrm{CBC}$, reticulocyte count, iron indices, creatinine, $\mathrm{Ca}, \mathrm{Po}$, parathyroid hormone (PTH), urea reduction ratio $(\mathrm{URR})=\frac{\text { Pre BUN-Post BUN }}{\text { Pre BUN }} \times 100$ together with hs-CRP titer and serum hepcidin level by the human hepcidin-25 ELISA kit E3096Hu, manufactured by Bioassay technology laboratory, Shanghai Korean Biotech Co., Ltd. These were drawn at baseline and after three months of oral vitamin $\mathrm{C}$ therapy.

The hepcidin kit is an enzyme-linked immunosorbent assay (ELISA). HEPC25 present in the sample was added

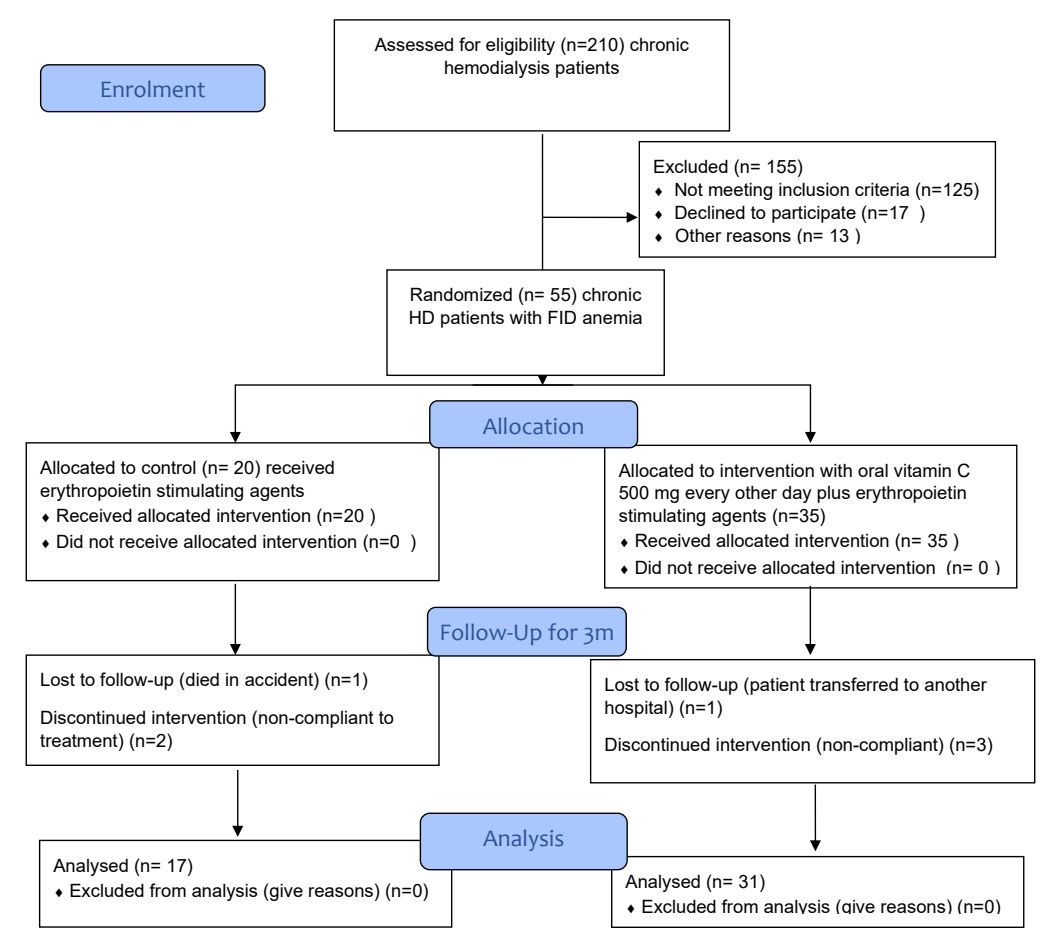

Figure 1. CONSORT Flow diagram of the study. 
to the wells and bound to human HEPC25 antibodies pre-coated on the wells. Then biotinylated human HEPC25 antibody was added and bound to HEPC25 in the sample. Streptavidin-HRP was then added and bound to the biotinylated HEPC25 antibody. After incubation, unbound streptavidin-HRP has washed away during a washing step. Substrate solution was then added, and color developed in proportion to the amount of human HEPC25. The reaction was terminated by the addition of acidic stop solution and absorbance was measured at 450 $\mathrm{nm}$. Response to therapy was defined as patients with an increase in hemoglobin at least $1.0 \mathrm{~g} / \mathrm{dL}$ during the followup of 3 months. EPO resistance index was calculated, defined as average weekly EPO dose per $\mathrm{kg}$ body weight (wt) per average hemoglobin $(\mathrm{Hgb})(\mathrm{ERI}=(\mathrm{EPO} / \mathrm{wt}) /$ $\mathrm{Hgb})$.

\section{Statistical methods}

Analysis of data was conducted using SPSS program version 23. Quantitative data were presented as mean and standard deviation. Qualitative data were presented as count and percentage. The student $t$ test was applied to compare quantitative data between two groups and one-way ANOVA was used when more than two groups were to be compared. Mann-Whitney $U$ test was used to compare non-parametric quantitative data between two groups. Paired samples $t$ test was applied to compare paired observations of quantitative data for the same group and the Wilcoxon signed ranks test was used for non-parametric data. Repeated measure ANOVA test was used to compare the change in quantitative data over time. The chi-square $\left(\chi^{2}\right)$ test was used to compare qualitative data between different groups, Pearson's correlation test was used to compare the correlation between different continuous variables. $P$ value $<0.05$ was considered statistically significant.

Results

The present study included 13 (41.9\%) males and 18 (58.1\%) females in the study group with a mean age \pm SD $46.48 \pm 15.57$ years versus $8(47.1 \%)$ males and 9 (52.9\%) females in the control group with mean age \pm SD $46.82 \pm 16.74$ years. The mean of time on dialysis in the study group and control group was $4.12 \pm 1.10$ and 3.28 \pm 2.03 years respectively. Among the study group, the most common causes of renal failure were hypertension (32.3\%) and diabetes mellitus (12.9\%) among others, while in the control group; the most common causes were hypertension (47.1\%), diabetes mellitus (11.8\%), glomerulonephritis (11.8\%) and unknown causes (11.8\%). Adequate dialysis was ensured in both groups as assessed by mean URR of $68 \%$ and $64 \%$ in the study and control groups, respectively. The baseline studied laboratory investigations were described in Table 1, with no statistically significant differences regarding the baseline studied parameters between the two groups of patients.

Hepcidin levels showed a statistically significant reduction in the study group after three months of oral vitamin $\mathrm{C}$ therapy $(P=0.03)$, while hepcidin levels showed no significant reduction in the control group after three months $(P=0.46)$ as shown in Table 2.

For hepcidin levels, there was no significant "withinsubjects" effect regarding time indicating an insignificant change in the mean hepcidin level over time alone

Table 1. Comparison between the two groups regarding lab investigations before intervention

\begin{tabular}{|c|c|c|c|c|c|c|}
\hline & \multicolumn{2}{|c|}{ Study group } & \multicolumn{2}{|c|}{ Control group } & \multirow{2}{*}{$\mathbf{t}^{*}$} & \multirow{2}{*}{$P$ value } \\
\hline & Mean & SD & Mean & SD & & \\
\hline Hemoglobin (g/dL) & 9.69 & 0.82 & 9.81 & 0.87 & 0.47 & $0.64 \mathrm{NS}$ \\
\hline Iron (ug/dL) & 72.17 & 26.22 & 67.64 & 28.27 & 0.56 & $0.58 \mathrm{NS}$ \\
\hline Ferritin (ng/mL) & 971.96 & 526.34 & 1159.25 & 481.90 & 01.21 & $0.23 \mathrm{NS}$ \\
\hline TIBC (ug/dL) & 213.59 & 33.02 & 221.75 & 33.35 & 0.82 & $0.42 \mathrm{NS}$ \\
\hline T Sat (\%) & 0.29 & 0.14 & 0.31 & 0.12 & 1.00 & $0.32 \mathrm{NS}$ \\
\hline Retic count & 1.39 & 0.65 & 1.25 & 0.55 & 0.75 & $0.46 \mathrm{NS}$ \\
\hline EPO resistance index & 11.53 & 7.97 & 11.63 & 5.93 & 0.04 & $0.97 \mathrm{NS}$ \\
\hline PTH (pg/mL) & 475.97 & 345.03 & 643.35 & 489.05 & 1.38 & $0.17 \mathrm{NS}$ \\
\hline $\mathrm{Ca}(\mathrm{mg} / \mathrm{dL})$ & 8.54 & 1.10 & 8.64 & 0.84 & 0.33 & $0.74 \mathrm{NS}$ \\
\hline PO4 (mg/dL) & 4.37 & 1.23 & 4.49 & 1.29 & 0.32 & $0.75 \mathrm{NS}$ \\
\hline Urea 1 (mg/dL) & 100.42 & 36.17 & 92.76 & 27.11 & 1.12 & $0.83 \mathrm{NS}$ \\
\hline Urea 2 (mg/dL) & 32.19 & 18.94 & 26.59 & 10.23 & 1.33 & $0.19 \mathrm{NS}$ \\
\hline Urea reduction ratio (\%) & 0.68 & 0.13 & 0.64 & 0.11 & 1.17 & $0.25 \mathrm{NS}$ \\
\hline $\mathrm{K}(\mathrm{mmol} / \mathrm{L})$ & 5.30 & 0.72 & 5.29 & 0.89 & 0.01 & $0.99 \mathrm{NS}$ \\
\hline Hepcidin (pg/mL) & 2506.45 & 1320.53 & 3161.76 & 1034.48 & -1.767 & $0.084 \mathrm{NS}$ \\
\hline hs-CRP (ng/mL) & 8603.23 & 2547.77 & 7044.12 & 2778.37 & 1.964 & $0.056 \mathrm{NS}$ \\
\hline
\end{tabular}

TIBC, Total iron-binding capacity; T Sat, transferrin serum iron saturation; PTH, parathormone; Ca, calcium; PO4, phosphorus; Urea 1, urea pre-dialysis; Urea 2, urea post-dialysis; K, potassium; hs-CRP, highly sensitive C-reactive protein; EPO, erythropoietin.

* Student $t$ test. 
Table 2. Comparison between studied variables before and after intervention among patients' groups

\begin{tabular}{|c|c|c|c|c|c|c|}
\hline \multirow{2}{*}{ Variables } & \multicolumn{3}{|c|}{ Study group (Vitamin C) } & \multicolumn{3}{|c|}{ Control group } \\
\hline & Before (Mean $\pm \mathrm{SD}$ ) & After (Mean \pm SD) & $P$ value* & Before (Mean $\pm \mathrm{SD})$ & After (Mean \pm SD) & $P$ value* \\
\hline Hepcidin (pg/mL) & $2506.4 \pm 1320.53$ & $1748.3 \pm 1432.28$ & 0.03 & $3161.76 \pm 1034.48$ & $3195.88 \pm 998.91$ & 0.46 \\
\hline hs-CRP (ng/mL) & $8603.2 \pm 2547.77$ & $5611.2 \pm 2829.27$ & 0.001 & $4061.7 \pm 2880.62$ & $2158.8 \pm 1736.76$ & 0.001 \\
\hline Hemoglobin (g/dL) & $9.69 \pm 0.82$ & $10.18 \pm 1.24$ & 0.09 & $9.81 \pm 0.87$ & $10.19 \pm 1.36$ & 0.12 \\
\hline Iron (ug/dL) & $72.17 \pm 26.22$ & $57.28 \pm 30.01$ & 0.02 & $67.64 \pm 28.27$ & $59.59 \pm 26.53$ & 0.29 \\
\hline Ferritin $(\mathrm{ng} / \mathrm{mL})=$ & $869.60 \pm 793.30$ & $546.20 \pm 874.30$ & 0.01 & $1159.2 \pm 481.90$ & $635.54 \pm 436.16$ & 0.001 \\
\hline TIBC (ug/dL) & $213.59 \pm 33.02$ & $192.63 \pm 25.85$ & 0.001 & $221.75 \pm 33.35$ & $189.70 \pm 33.06$ & 0.01 \\
\hline T Sat (\%) & $35 \pm 14$ & $30 \pm 15$ & 0.12 & $0.31 \pm 0.12$ & $0.32 \pm 0.14$ & 0.82 \\
\hline Retic counts & $1.39 \pm 0.65$ & $0.84 \pm 0.52$ & 0.001 & $1.25 \pm 0.55$ & $0.78 \pm 0.72$ & 0.05 \\
\hline EPO dose (IU) (average/week) & $7142.8 \pm 3147.18$ & $6229.7 \pm 3218.44$ & 0.26 & $8000.0 \pm 3023.72$ & $5666.4 \pm 2807.45$ & 0.06 \\
\hline EPo resistance index & $11.53 \pm 7.97$ & $9.75 \pm 7.34$ & 0.14 & $11.63 \pm 5.93$ & $8.88 \pm 5.79$ & 0.11 \\
\hline
\end{tabular}

TIBC, Total iron-binding capacity; T Sat, transferrin serum iron saturation; hs-CRP, highly sensitive C-reactive protein; EPO, erythropoietin.

* Paired Samples $t$ test; $*$ Significant $P$ value $<0.05$.

$(P=0.09)$. The "between subjects' effect" was statistically significant $(P=0.029)$ indicating that the mean hepcidin level differed significantly between the two groups. The interaction between time and group variables $(P=0.04)$ illustrates that vitamin $C$ together with time resulted in a significant reduction of hepcidin levels in the study group as shown in Table 3 and Figure 2.

Highly sensitive CRP levels showed a highly significant reduction in the study group $(P<0.01)$ as shown in, while hs-CRP levels also showed a highly significant reduction in the control group $(P<0.01)$ as shown in Table 2. For hsCRP, there was a highly significant "within-subjects" effect indicating a significant change in the mean hs-CRP level over time $(P<0.01)$ as shown in Table 4 . The "betweensubjects effect" was statistically highly significant $(P<0.01)$ indicating that the mean hs-CRP level differed significantly between the study groups. There was a highly significant correlation between baseline hepcidin levels and baseline hs-CRP levels $(P<0.01)$.

Regarding ferritin, as shown in, the study group showed a highly significant reduction in ferritin levels $(P=0.01)$, among the control group also showed a highly significant reduction in ferritin levels $(P<0.01)$ as shown in (Table 2). Comparison between two groups during the follow-up revealed that for serum ferritin, there was no significant "within-subjects" effect indicating an insignificant change in the mean serum ferritin level over time $(P>0.05)$. The "between-subjects effect" was statistically insignificant $(P>0.05)$ indicating that the mean serum ferritin level did not differ significantly between the study groups. There was no interaction between time and group variables.

Regarding other iron indices, the study group showed a statistically significant reduction in iron levels $(\mathrm{P}<0.05)$. Total iron binding capacity (TIBC) and reticulocyte count showed highly significant reductions $(P<0.01)$ as shown in Table 2. The control group showed a highly significant reduction in TIBC $(P=0.01)$ and a significant reduction in Retics $(P=0.05)$ as shown in Table 2. There were no significant reductions in iron levels and TSAT after three months.

There was no statistically significant difference between the study and control groups regarding hemoglobin response to therapy, defined as an elevation in hemoglobin

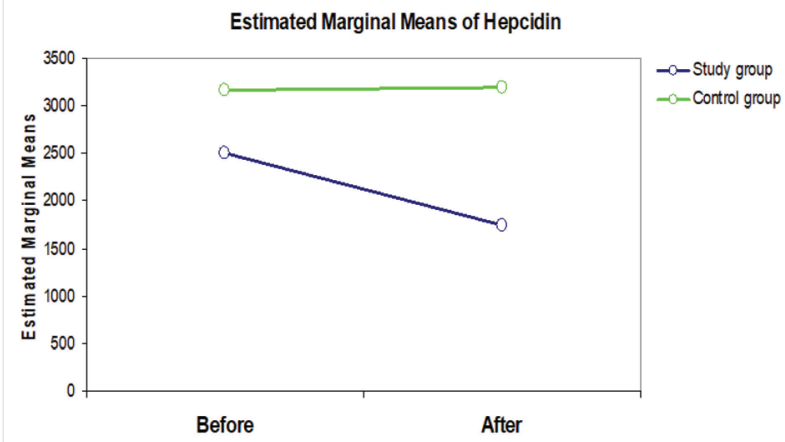

Figure 2. Comparison between the two groups regarding changes in Hepcidin levels during follow-up.

Table 3. Comparison between the two groups regarding changes in hepcidin levels during follow up

\begin{tabular}{|c|c|c|c|c|c|c|c|}
\hline \multirow{2}{*}{ Hepcidin level (pg/mL) } & \multicolumn{2}{|c|}{ Study group } & \multicolumn{2}{|c|}{ Control group } & \multicolumn{2}{|c|}{ Within subject effect } & \multirow{2}{*}{$\begin{array}{l}\text { Between subject effect } \\
\text { Group }\end{array}$} \\
\hline & Mean & SD & Mean & SD & Time & Time*group & \\
\hline Before & 2506.4 & 1320.5 & 3161.76 & 1034.48 & 0.09 & 0.04 & 0.029 \\
\hline After & 1748.3 & 1432.2 & 3195.88 & 998.91 & NS & & \\
\hline
\end{tabular}


Table 4. Comparison between two groups regarding change in hs-CRP levels during follow up

\begin{tabular}{|c|c|c|c|c|c|c|c|}
\hline \multirow{2}{*}{ Hepcidin level (pg/mL) } & \multicolumn{2}{|c|}{ Study group } & \multicolumn{2}{|c|}{ Control group } & \multicolumn{2}{|c|}{ Within subject effect } & \multirow{2}{*}{$\begin{array}{l}\text { Between subject effect } \\
\text { Group }\end{array}$} \\
\hline & Mean & SD & Mean & SD & Time & Time*group & \\
\hline Before & 8603.2 & 2547.7 & 4061.7 & 2880.6 & \multirow{2}{*}{$<0.001$} & \multirow{2}{*}{0.33} & \multirow{2}{*}{$<0.001^{*}$} \\
\hline After & 5611.2 & 2829.2 & 2158.8 & 1736.7 & & & \\
\hline
\end{tabular}

* Significant $P$ value $<0.05$

level $\geq 1 \mathrm{~g} / \mathrm{dL}\left(\chi^{2}=0.202, \mathrm{P}>0.05\right)$. In the study group, $13(41.9 \%)$ patients showed elevation $\geq 1 \mathrm{~g} / \mathrm{dL}$ while 18 (58.1\%) patients did not show elevation. In the control group, $6(35.3 \%)$ patients in the control group showed elevation $\geq 1 \mathrm{~g} / \mathrm{dL}$ while 11 (64.7\%) patients did not show elevation.

There were no significant reductions in erythropoietin dose or hemoglobin levels in the study group after three months of oral vitamin $\mathrm{C}$ therapy. The control group showed no significant reduction in erythropoietin dose or hemoglobin levels. The erythropoietin resistance index showed a reduction in the study and control groups after intervention but was not statistically significant $(P>0.05)$.

There were no significant correlations between baseline hepcidin levels and gender, cause of renal failure, age, weight, body mass index, erythropoietin dose, hemoglobin levels, iron indices, reticulocyte count, or serum electrolytes. The study group showed nonsignificant changes in other studied parameters as PTH, potassium $(\mathrm{K})$, calcium, and phosphate $\left(\mathrm{PO}_{4}\right)$ in both groups after three months.

\section{Discussion}

This study found that hepcidin levels were higher in both the study and control groups of prevalent HD patients compared to the normal reference ranges which are in agreement with multiple studies as Xu et al (6), Kuragano et al (7), and Peters et al (8), who found high levels of hepcidin among HD patients compared to healthy controls. High hepcidin levels are contributed to increased production resulting from the chronic inflammatory status seen in end-stage renal disease patients and due to its reduced renal clearance. In the current study, we observed that oral vitamin $\mathrm{C}$ therapy resulted in a significant reduction in hepcidin levels in the study group; while, the control group showed a non-significant reduction.

In agreement with our study, when Chiu et al (9), cultured hepcidin-producing HepG2 cells from the liver with $50-100 \mathrm{mg} / \mathrm{mL}$ vitamin $\mathrm{C}$ for six hours with reverse transcription PCR (polymerase chain reaction) quantitative hepcidin measurements, he found a depression in hepcidin production and an improvement in the utilization of stored iron and concluded that vitamin C directly inhibits hepcidin expression within HepG2 cells, additionally may correct the downregulating EPO receptor. Limited clinical studies are examining the link between serum hepcidin and vitamin $\mathrm{C}$ among chronic kidney disease and HD patients.

The significant reduction in hs-CRP levels among HD received oral vitamin $C$ supplementation in the present study agreed with Biniaz et al (10), who confirmed that among the $151 \mathrm{HD}$ patients involved, hs-CRP levels decreased more obviously in the intravenous vitamin $\mathrm{C}$ supplemented group than in the control group ( $\mathrm{P}=0.028)$. In comparison, our study showed a highly significant reduction in the control group as well.

Our study reported a highly significant correlation between baseline hepcidin levels and baseline hs-CRP levels. There were no other significant correlations between baseline hepcidin levels and gender, cause of renal failure, age, weight, body mass index, erythropoietin dose, hemoglobin levels, iron indices, reticulocyte count, or serum electrolytes. In contrast to our study, Kuragano et al (7), found a highly significant correlation between hepcidin and iron indices (iron, transferrin, TSAT and ferritin). Fujita et al (11), demonstrated a strong positive correlation between serum ferritin and hepcidin mRNA expression. This can be explained by the fact that hepcidin primarily regulates the liver iron content, which would, in turn, regulate serum ferritin levels via hepatic iron content because hepatocytes and Kupffer cells also express ferroportin. In agreement with our study, Kuragano et al (7), found that hepcidin level was not correlated with age, gender, gender, hemoglobin levels, erythropoietin dose or serum electrolytes.

The present study showed that vitamin C therapy resulted in a highly significant reduction in ferritin levels after intervention in the study group but this was also observed in the control group. In agreement, Sultana et al (12), showed a significant reduction in ferritin after oral vitamin $\mathrm{C}$ therapy in the ascorbate group. In contrast, Deved et al (13), assessed the effect of ascorbic acid on iron indices in five trials (14-18) and showed a small non-significant decrease in ferritin concentration in intravenous-ascorbic acid supplemented users over controls, although this result did not achieve statistical significance.

The current study showed that oral vitamin C therapy resulted in a non-significant reduction in TSAT and a significant reduction in TIBC; in contrast, six trials (1419) showed a statistically significant increase in TSAT for the intravenous-ascorbic acid group compared with controls. In agreement with our study, Atallah et al (15), showed that the intravenous-ascorbate supplemented 
group was associated with a decrease in TIBC, an indicator of improved iron delivery to tissues.

The present study showed no statistically significant difference between the study and control groups regarding hemoglobin response to therapy, defined as an elevation in hemoglobin level $\geq 1 \mathrm{~g} / \mathrm{dl}$, which may be attributed to the short-term period of the present study. In contrast to our study, a systematic review by Deved et al (13), examining the effects of intravenous ascorbic acid on hemoglobin concentration in HD patients included three trials $(n=125)$ with baseline hemoglobin levels $<11 \mathrm{~g} / \mathrm{dL}$ and reported mean changes in hemoglobin concentration $0.8-1.8 \mathrm{~g} / \mathrm{dL}$ in the ascorbic acid groups and -0.1 to 1.1 $\mathrm{g} / \mathrm{dL}$ in the control groups. The change in hemoglobin concentration was statistically significant, with ascorbic acid use resulting in a $0.9 \mathrm{~g} / \mathrm{dL}$ increase in hemoglobin level compared with controls.

Our study showed that oral vitamin $\mathrm{C}$ resulted in a decrease in EPO dose in the study group (12 U/kg/wk) but was less than in the control group ( $34 \mathrm{U} / \mathrm{kg} / \mathrm{wk})$. In contrast, Atallah et al (15), showed that intravenous vitamin C decreased EPO doses significantly greater among HD patients in the experimental ascorbate patients ( $48 \mathrm{U} / \mathrm{kg} / \mathrm{wk}$ ) than in control patients $(27 \mathrm{U} / \mathrm{kg} / \mathrm{wk})$. It may be attributed to the variability of EPO doses available used by patients in different studies and also oral vitamin $\mathrm{C}$ has different pharmacokinetics than intravenous vitamin C.

Other contrasting studies as Sultana et al (12), demonstrated a significant decrease in EPO dose requirements with low-dose oral vitamin $\mathrm{C}$ in anemic HD patients with FID over three months. David et al (13), also showed a mean change in recombinant human erythropoietin (rHuEPO) dose ranging from -48 to $1 \mathrm{U} /$ $\mathrm{kg} / \mathrm{wk}$ in the ascorbic acid groups and -27 to $10 \mathrm{U} / \mathrm{kg} /$ wk in the control groups in six trials (14-19) including $(n=303)$ patients. The use of ascorbic acid was associated with a significant decrease in rHuEPO dose compared with controls. In our study, the erythropoietin resistance index showed a non-significant reduction in the study and control groups after intervention.

Vitamin C is known for its strong anti-inflammatory role and its antioxidant nature that may explain its effects on the inflammatory mediators as hepcidin and hs-CRP but it is used requires caution as it is metabolized into oxalic acid, and excess oxalate accumulation leads to the formation of oxalate crystal deposits in tissues and systemic oxalosis (20). Therefore, most of the previous studies were designed to be a short duration of administration of intravenous vitamin $\mathrm{C}$ for limitation of estimation serum oxalate and to minimize the risk of oxalosis among HD patients. Our study was designed with a low dose of oral ascorbic acid (vitamin C) which has the advantage of easy availability and cost-effectiveness over the moderate duration.

\section{Conclusion}

There is a direct relationship between ascorbic acid (vitamin C) and serum hepcidin level among chronic kidney disease patients. Oral vitamin $C$ may be a promising therapy in decreasing serum hepcidin levels and inflammatory markers as hs-CRP and ferritin levels in prevalent HD patients with FID anemia. For further larger cohort studies to investigate the long-term effect of vitamin $\mathrm{C}$ low doses as adjuvant therapy on hepcidin level and reducing erythropoietin requirement or improving hyperferritinemia among HD patients.

\section{Limitations of this study}

The limitations of this study are; this it is a pilot study with small sample size. Serum vitamin C and oxalate levels were not measured.

\section{Authors' contribution}

$\mathrm{MB}$ has made substantial contributions to the conception and design of this study, revised and analyzed the patient data, involved in drafting of the manuscript and revising it for important intellectual content and has given final approval of the version to be published. MZ made substantial contributions to conception and design, revised and analyzed the patient data and has given final approval of the version to be published. AH made substantial contributions to acquisition of data, writing the manuscript and has given final approval of the version to be published. RE made substantial contributions to conception and design, analysis and interpretation of data, and drafting the manuscript. All authors read and approved the final manuscript file

\section{Conflicts of interest}

The authors declare that there is no conflict of interest.

\section{Ethical issues}

All the procedures conducted in the study followed the ethical standards of Ain Shams University Hospital Research Committee (Ethics Committee reference number: 000017585) and the ethical standards laid down in the 1964 Declaration of Helsinki. Informed written consent was obtained from all the patients enrolled in the study. Accordingly, ethical issues (including plagiarism, data fabrication, double publication) have been completely observed by the authors.

\section{Funding/Support}

No funding was received.

\section{References}

1. Hentze MW, Muckenthaler MU, Galy B, Camaschella C. Two to tango: regulation of Mammalian iron metabolism. Cell. 2010;142:24-38. doi: 10.1016/j.cell.2010.06.028.

2. Handelman GJ. New insight on vitamin $C$ in patients with chronic kidney disease. J Ren Nutr. 2011;21:110-2. doi: 10.1053/j.jrn.2010.11.003.

3. Malyszko J, Mysliwiec M. Hepcidin in anemia and inflammation in chronic kidney disease. Kidney Blood Press Res. 2007;30:15-30. doi: 10.1159/000098522.

4. Shike H, Lauth X, Westerman ME, Ostland VE, Carlberg JM, Van Olst JC, et al. Bass hepcidin is a novel antimicrobial peptide induced by bacterial challenge. Eur J Biochem. 2002;269:2232-7. doi: 10.1046/j.1432-1033.2002.02881.x.

5. Thomas DW, Hinchliffe RF, Briggs C, Macdougall IC, Littlewood T, Cavill I, et al. Guideline for the laboratory diagnosis of functional iron deficiency. Br J Haematol. 2013;161:639-48. doi: 10.1111/bjh.12311. 
6. Xu Y, Ding XQ, Zou JZ, Liu ZH, Jiang SH, Chen YM. Serum hepcidin in haemodialysis patients: associations with iron status and microinflammation. J Int Med Res. 2011;39):19617. doi: $10.1177 / 147323001103900542$.

7. Kuragano T, Shimonaka Y, Kida A, Furuta M, Nanami M, Otaki $\mathrm{Y}$, et al. Determinants of hepcidin in patients on maintenance hemodialysis: role of inflammation. Am J Nephrol. 2010;31:534-40. doi: 10.1159/000312381.

8. Peters HP, Laarakkers CM, Swinkels DW, Wetzels JF. Serum hepcidin-25 levels in patients with chronic kidney disease are independent of glomerular filtration rate. Nephrol Dial Transplant. 2010;25:848-53. doi: 10.1093/ndt/gfp546.

9. Chiu PF, Ko SY, Chang CC. Vitamin C affects the expression of hepcidin and erythropoietin receptor in HepG2 cells. J Ren Nutr. 2012;22:373-6. doi: 10.1053/j.jrn.2011.09.007.

10. Biniaz V, Sadeghi Shermeh M, Ebadi A, Tayebi A, Einollahi B. Effect of Vitamin C Supplementation on C-reactive Protein Levels in Patients Undergoing Hemodialysis: A Randomized, Double Blind, Placebo-Controlled Study. Nephrourol Mon. 2013;6:e13351. doi: 10.5812/numonthly.13351.

11. Fujita N, Sugimoto R, Takeo M, Urawa N, Mifuji R, Tanaka H, et al. Hepcidin expression in the liver: relatively low level in patients with chronic hepatitis C. Mol Med. 2007;13:97-104. doi: 10.2119/2006-00057.Fujita.

12. Sultana $T$, DeVita MV, Michelis MF. Oral vitamin C supplementation reduces erythropoietin requirement in hemodialysis patients with functional iron deficiency. Int Urol Nephrol. 2016;48:1519-24. doi: 10.1007/s11255-016-13099.

13. Deved V, Poyah P, James MT, Tonelli M, Manns BJ, Walsh M, et al. Ascorbic acid for anemia management in hemodialysis patients: a systematic review and meta-analysis. Am J Kidney Dis. 2009;54:1089-97. doi: 10.1053/j.ajkd.2009.06.040.

14. Sezer S, Ozdemir FN, Yakupoglu U, Arat Z, Turan M, Haberal M. Intravenous ascorbic acid administration for erythropoietinhyporesponsive anemia in iron loaded hemodialysis patients. Artif Organs. 2002;26:366-70. doi: 10.1046/j.15251594.2002.06888.x

15. Attallah N, Osman-Malik Y, Frinak S, Besarab A. Effect of intravenous ascorbic acid in hemodialysis patients with EPOhyporesponsive anemia and hyperferritinemia. Am J Kidney Dis. 2006;47:644-54. doi: 10.1053/j.ajkd.2005.12.025.

16. Chan D, Irish A, Dogra G. Efficacy and safety of oral versus intravenous ascorbic acid for anaemia in haemodialysis patients. Nephrology (Carlton). 2005;10:336-40. doi: 10.1111/j.1440-1797.2005.00424.x. PMID: 16109077.

17. Deira J, Diego J, Martínez R, Oyarbide A, González A, Díaz $\mathrm{H}$, Grande J. Comparative study of intravenous ascorbic acid versus low-dose desferroxamine in patients on hemodialysis with hyperferritinemia. J Nephrol. 2003;16:703-9.

18. Giancaspro V, Nuzziello M, Pallotta G, Sacchetti A, Petrarulo F. Intravenous ascorbic acid in hemodialysis patients with functional iron deficiency: a clinical trial. J Nephrol. 2000;13:444-9.

19. Keven K, Kutlay S, Nergizoglu G, Ertürk S. Randomized, crossover study of the effect of vitamin C on EPO response in hemodialysis patients. Am J Kidney Dis. 2003;41:1233-9. doi: 10.1016/s0272-6386(03)00356-1.

20. Handelman GJ. New insight on vitamin $C$ in patients with chronic kidney disease. J Ren Nutr. 2011;21:110-2. doi: 10.1053/j.jrn.2010.11.003. 